\title{
Cerebral Amyloid Angiopathy
}

National Cancer Institute

\section{Source}

National Cancer Institute. Cerebral Amyloid Angiopathy. NCI Thesaurus. Code C84625.

A disorder characterized by the deposition of amyloid in the wall of the vessels in the brain. 